\title{
Biological effects within no-take marine reserves: a global synthesis
}

\author{
Sarah E. Lester ${ }^{1, *}$, Benjamin S. Halpern ${ }^{2}$, Kirsten Grorud-Colvert ${ }^{3}$, Jane Lubchenco ${ }^{3}$, \\ Benjamin I. Ruttenberg ${ }^{4}$, Steven D. Gaines ${ }^{5}$, Satie Airamé ${ }^{1}$, Robert R. Warner ${ }^{5}$ \\ ${ }^{1}$ Marine Science Institute, University of California, Santa Barbara, California 93106-6150, USA \\ ${ }^{2}$ National Center for Ecological Analysis and Synthesis, 735 State Street, Suite 300, Santa Barbara, California 93101, USA \\ ${ }^{3}$ Department of Zoology, 3029 Cordley Hall, Oregon State University, Corvallis, Oregon 97331-2914, USA \\ ${ }^{4}$ National Marine Fisheries Service, Southeast Fisheries Science Center, 75 Virginia Beach Drive, Miami, Florida 33149, USA \\ ${ }^{5}$ Department of Ecology, Evolution, and Marine Biology and Marine Science Institute, University of California, \\ Santa Barbara, California 93106-9610, USA
}

\begin{abstract}
The study and implementation of no-take marine reserves have increased rapidly over the past decade, providing ample data on the biological effects of reserve protection for a wide range of geographic locations and organisms. The plethora of new studies affords the opportunity to reevaluate previous findings and address formerly unanswered questions with extensive data syntheses. Our results show, on average, positive effects of reserve protection on the biomass, numerical density, species richness, and size of organisms within their boundaries which are remarkably similar to those of past syntheses despite a near doubling of data. New analyses indicate that (1) these results do not appear to be an artifact of reserves being sited in better locations; (2) results do not appear to be driven by displaced fishing effort outside of reserves; (3) contrary to often-made assertions, reserves have similar if not greater positive effects in temperate settings, at least for reef ecosystems; (4) even small reserves can produce significant biological responses irrespective of latitude, although more data are needed to test whether reserve effects scale with reserve size; and (5) effects of reserves vary for different taxonomic groups and for taxa with various characteristics, and not all species increase in response to reserve protection. There is considerable variation in the responses documented across all the reserves in our data set — variability which cannot be entirely explained by which species were studied. We suggest that reserve characteristics and context, particularly the intensity of fishing outside the reserve and inside the reserve before implementation, play key roles in determining the direction and magnitude of the reserve response. However, despite considerable variability, positive responses are far more common than no differences or negative responses, validating the potential for well designed and enforced reserves to serve as globally important conservation and management tools.
\end{abstract}

KEY WORDS: Marine reserves · Temperate - Tropical · Fishes · Invertebrates · Algae $\cdot$ Marine Protected Area · Conservation

Resale or republication not permitted without written consent of the publisher

\section{INTRODUCTION}

The world's oceans face an increasing number and severity of threats, including overexploitation of living marine resources, habitat degradation and destruction, pollution, and climate change impacts (Harley et al. 2006, UNEP 2006, Halpern et al. 2008, Jackson 2008). These various stressors in turn lead to depleted populations of economically and culturally important species, altered community structure, and compromised eco- 
system functioning and delivery of services. The scope of these changes spans many habitats, species, and different trophic levels, and thus may require more holistic, ecosystem-based management approaches (Lubchenco et al. 2003, Browman \& Stergiou 2004, UNEP 2006). Because marine reserves protect all species and habitats in an area from extractive activities, they are a central tool for ecosystem-based management and offer hope for mitigating some of the threats affecting coastal and marine systems (Worm et al. 2006).

Marine reserves are defined here as 'areas of the ocean completely protected from all extractive and destructive activities... except as necessary for monitoring or research' (Lubchenco et al. 2003, p. S3). Marine reserves are an important subset of Marine Protected Areas (MPAs). MPAs vary greatly in their regulations and their utility for conservation likely varies considerably based on the level of protection afforded, making it difficult to generalize about the benefits of MPAs (Mora et al. 2006, Lester \& Halpern 2008). Although MPAs with less restrictive regulations are undoubtedly important management tools, no-take marine reserves offer the greatest protection for marine resources and ecosystems and thus are the sole focus of the present study. Marine reserves have received increasing attention over the last few decades as an important management strategy for both conservation and fisheries management goals (Halpern 2003, Halpern \& Warner 2003, Palumbi et al. 2003, Leslie 2005, Claudet et al. 2008, White et al. 2008).

Numerous syntheses of monitoring studies have documented how population numbers and biomass, organism size, species richness, reproductive potential, and/or community structure are affected by reserve protection (Halpern \& Warner 2002, Palumbi 2002, Gell \& Roberts 2003, Halpern 2003, Micheli et al. 2004). Many of these studies suggest that beneficial effects of reserve protection are common. This is particularly evident when comparing numerical density and biomass of exploited species inside and outside reserves and/or before and after reserve protection (Côté et al. 2001, Gell \& Roberts 2003, Halpern 2003). On the other hand, some authors have suggested that the impacts of reserves may be idiosyncratic, varying with the goal(s) set by the body or institution establishing the reserve, whether the reserve is part of a network of reserves, the location, size, and protection duration of the reserve, and the characteristics of the species under consideration (Jennings 2000, Mosqueira et al. 2000, Côté et al. 2001, Micheli et al. 2004, Kaiser 2005, Claudet et al. 2008). Therefore, although there is encouraging evidence that reserves are an effective management option for restoring and sustaining marine ecosystems within their boundaries, some important questions about the utility of reserves remain unresolved.
In particular, contention exists about whether reserve effects will be different in temperate versus tropical regions (Blyth-Skyrme et al. 2006). A number of authors have suggested that temperate reserves might result in smaller or no changes in exploited species because of 2 primary reasons. (1) Exploited species in temperate regions tend to be more mobile and are thus less likely to benefit from a reserve (Shipp 2003, Kaiser 2004). If most individuals stray beyond reserve borders, their populations will not be effectively protected. (2) Temperate species and populations tend to have longer larval durations and thus greater larval dispersal potential and gene flow than their tropical counterparts (Laurel \& Bradbury 2006, O'Connor et al. 2006).

Given potentially higher rates of adult movement and larval export, it has been suggested that reserves in temperate systems may need to be larger than tropical reserves to achieve comparable results (Laurel \& Bradbury 2006). Comparisons across reserves in different locations suggest that changes in biological metrics do not vary appreciably with reserve size (Côté et al. 2001, Halpern 2003, Micheli et al. 2004, Guidetti \& Sala 2007, but see Claudet et al. 2008). However, reserve size has not been examined with respect to geographical differences among reserves. Additionally, there is a perception that most of the positive effects of marine reserves have been documented in tropical systems or that tropical reserves have received more attention in scientific studies (Blyth-Skyrme et al. 2006, Laurel \& Bradbury 2006). In fact, there are many scientific studies of temperate reserves, with peerreviewed publications from a variety of regions (see Fig. 1) such as Australia, New Zealand, the Mediterranean, North America, South America, and South Africa (e.g. Paddack \& Estes 2000, Manriquez \& Castilla 2001, Shears \& Babcock 2003, Mayfield et al. 2005, Micheli et al. 2005). However, the present study is the first meta-analysis explicitly comparing the results from tropical and temperate reserves.

Marine reserve protection is also likely to affect individual species differently, based on whether they are exploited or otherwise affected by activities outside the reserve; biological characteristics such as mobility, dispersal ability, longevity, and fecundity; the nature of density dependence; and indirect effects resulting from interactions with other species that are directly affected by reserve protection (Mosqueira et al. 2000, Fisher \& Frank 2002, Gaines et al. 2003, Micheli et al. 2004, Gaylord et al. 2005, Gerber et al. 2005, Kaiser 2005). Although different responses may be expected for different taxonomic groups, this issue has primarily been investigated for fish species (e.g. Micheli et al. 2004). However, there is a growing body of data not only for fishes, but also for invertebrates and algae 
from a range of geographic locations. In the present study, we investigate differences among broad taxonomic groupings and among invertebrate and algal functional groups in both tropical and temperate reserves.

Impacts of marine reserves generally fall into 2 broad categories: changes occurring inside versus those occurring outside the reserve. The latter includes both spillover of individuals from the reserve to the outside (Gell \& Roberts 2003, Sale et al. 2005, B. S. Halpern et al. unpubl. data) and export of larvae from the reserve (Botsford et al. 2001, Palumbi 2003). Because it is more straightforward to assess effects inside reserves and data are therefore more comparable and more readily available, this review will focus exclusively on effects within reserves by expanding the global assessment of reserve effects on basic biological measures. Specifically, we evaluate (1) the biological effects of marine reserves and whether these effects are likely an artifact from using primarily inside versus outside reserve comparisons, (2) whether reserves in temperate waters perform similarly to reserves in tropical systems, and (3) the magnitude of the biological effects of marine reserves on different taxonomic and functional groups.

\section{METHODS}

We conducted a comprehensive survey of the peerreviewed scientific literature to compile a database of studies that document biological effects of marine reserves (Table S1, available in MEPS Supplementary Material at www.int-res.com/articles/suppl/ m384p033_app.pdf). We included only peer-reviewed studies of fully-protected, no-take marine reserves and only those studies for which effects were measured for individual reserves. Studies must have measured at least 1 of 4 key biological variables (numerical density or biomass/area of organisms, individual organism size, or species richness/area) and must have quantified the variable(s) either (1) inside and outside the reserve, (2) before and after reserve implementation, or (3) inside and outside the reserve both before and after implementation. Throughout the text, tables, and figures, density refers to numerical density, not other density measures such as biomass.

The resulting database contains 149 peer-reviewed scientific publications published between 1977 and 2006 of 124 different marine reserves located in 29 countries (Fig. 1). Because some reserves were studied in more than one publication and some publications studied multiple reserves, the database includes 221 'studies.' For most of the reserves in the database ( $\mathrm{n}=$ 108), we were able to find a reliable estimate of its area $\left(\mathrm{km}^{2}\right)$. We classified each reserve as being located in either a temperate $(n=53)$ or tropical $(n=71)$ ecosystem based on latitude, region, and habitat.

For each study, we extracted quantitative data from text, tables, and figures for the 4 biological variables inside and outside the reserve, before and after implementation, or inside and outside the reserve before and after implementation. Data were extracted at the most aggregated taxonomic level available, even if the

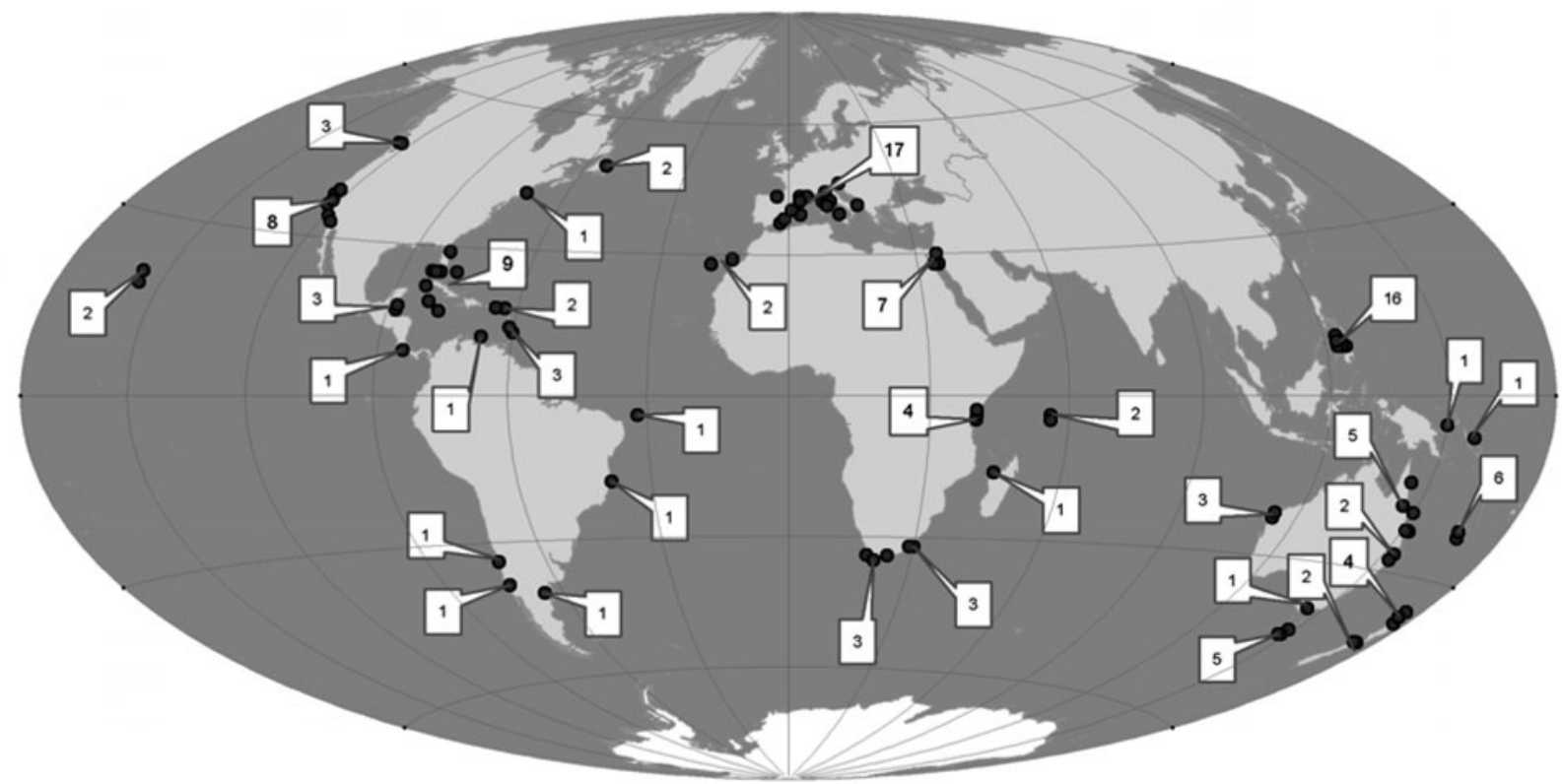

Fig. 1. Marine reserves $(\bullet, n=124)$ for which peer-reviewed scientific data are available (comment callouts indicate the number of reserves studied in different areas) 
level of taxonomic resolution differed within or among studies. For example, if a study reported data for particular fish families in addition to species level data for other fish families, all of these data were extracted (but species-level data for a fish family for which familylevel data were reported would not be extracted). If a study reported data in categories for both the reserve and control area (e.g. by depth, habitat type, or organism size classes), these values were averaged into single values. If multiple time steps of data were reported for an Outside/Inside comparison, we used the most recent data because they represent the longest duration of protection. In order to be used as a before/after or Before/After/Inside/Outside comparison, 'before' data must have been collected no later than 3 mo after reserve establishment. If data were collected at multiple times before reserve implementation, the data from the 'before' time steps were averaged unless there was an obvious trend prior to implementation (in which case the most recent data prior to implementation were extracted). We always used the most recent 'after' data to represent the longest duration of protection.

For algae and invertebrates, in addition to extracting data at the most aggregated taxonomic level, we also extracted data at the least aggregated taxonomic level available (i.e. ideally at the species level, but genera level or higher if species data were not reported). We assigned each algal datum to a morphological functional group, using a modified version of the categories developed by Steneck \& Dethier (1994): crustose algae, filamentous algae, articulated calcareous algae, corticated foliose algae, corticated macrophytes, and leathery macrophytes. For the invertebrate data, we assigned each datum to a phylum and a lower taxonomic group (Table 1). We also classified the invertebrates based on characteristics that might influence the effect of reserve

Table 1. Taxonomic classifications used for invertebrate-only analyses

\begin{tabular}{|ll|}
\hline Phylum & Taxonomic group \\
\hline Mollusca & $\begin{array}{l}\text { Gastropods } \\
\text { Bivalves } \\
\text { Echinodermata }\end{array}$ \\
& $\begin{array}{l}\text { Urchins } \\
\text { Sea cucumbers }\end{array}$ \\
Arthropoda & Barnacles \\
& Crabs \\
& Hermit crabs \\
Cnidaria & Lobsters \\
& Hard corals \\
& Soft corals \\
& Anthozoa (hard and soft corals) \\
Porifera & Hydrozoa \\
Annelida & Sponges \\
\end{tabular}

protection on biological metrics, including target status, trophic level, larval dispersal potential, and adult mobility (Table S2, available at www.int-res.com/articles/ suppl/m384p033_app.pdf). These data were examined in algae-only and invertebrate-only analyses to determine characteristics of these taxa that may mediate a reserve effect.

To quantify the effect of reserve protection using a comparable metric across studies, we calculated response ratios of the 4 biological variables as (1) the ratio of Inside to Outside, (2) the ratio of After to Before, or (3) the ratio of After to Before within the reserve, controlling for temporal changes outside the reserve ([After-Inside/Before-Inside]/[After-Outside/BeforeOutside]). Using the extracted data, we calculated response ratios within each study for each biological variable. When data were extracted for multiple taxa in a given study, we then averaged these response ratios to determine the overall (study) ratio for all taxa examined, regardless of how many species/taxa were studied. Overall (study) ratios represent from one to several hundred species depending on the study. Furthermore, if a study reported data separately for more than one of our broad taxonomic groups (fishes, invertebrates, and algae), we calculated an average for each group first and then averaged these group values to determine the overall ratio. This was done to give the best estimates of community-level responses; although in very few cases did this procedure yield a different value than the value obtained by averaging all data without calculating taxonomic group averages first.

Some reserves have been the subject of numerous published studies. We did not want to bias our analyses in favor of the most frequently studied reserves, so we calculated the average reserve ratio from all of the study ratios (and again for taxonomic group, algaeonly, and invertebrate-only study ratios) for reserves that were the subject of more than one study. We chose to calculate a reserve average rather than using the most recent study because often different studies of the same reserve varied in the taxa measured, the survey methods used, or in the investigators conducting the research. For reserves that were the subject of a single study, the reserve ratio is equivalent to the study ratio. We converted the ratios to percentage increases or decreases to facilitate interpretation ([response ratio $1] \times 100$; e.g. a density response ratio of 2.5 is equal to a $150 \%$ increase). These procedures were repeated for each of the 4 biological response variables.

The vast majority of the studies in our database (>90\%) compared data from inside versus outside the reserve. Because reserves can have effects outside their boundaries, using Inside versus Outside comparisons could potentially mask (because of larval export or adult spillover) or exaggerate (because of displace- 
ment of fishing effort or being placed in areas with better habitat) a true positive reserve effect. To address these issues, we examined the 23 studies in our database with data inside and outside of the reserve, before and after reserve implementation. For these studies, we calculated response ratios of (1) Inside-Before versus Outside-Before to test whether reserves are placed in 'better' locations, and (2) Outside-Before versus Outside-After to assess whether we might be under- or overestimating a reserve effect due to changes outside of the reserve (Halpern et al. 2004).

For all statistical analyses, we used the log of each ratio (Hedges et al. 1999) and the log of reserve size to meet statistical criteria and conducted all statistical tests using JMP 6.0 or SAS 9.1 (SAS Institute). We analyzed these data to answer 3 primary questions: (1) Are density, biomass, individual size, or species richness significantly and consistently affected by reserve protection? (2) Do changes in biomass, density, size, or richness inside a reserve differ in temperate versus tropical regions? and (3) Do the effects of reserves vary by taxonomic group or characteristics of the taxa under consideration?

\section{RESULTS AND DISCUSSION}

\section{Biological effects within marine reserves}

Examining the global data set, reserve protection resulted in statistically significant increases of all 4 of the key biological variables that we examined (Fig. 2). The most dramatic increases occurred in biomass and density of organisms within reserves (respectively, 446 and $166 \%$ average increases, 194 and $61 \%$ median increases). Individual size and species richness both showed positive but more moderate responses to reserve protection (respectively, 28 and $21 \%$ average increases, 17 and $15 \%$ median increases), a noteworthy result given that both of these parameters have much lower scope for change relative to density or biomass (the product of increases in individual size and density). For example, a $20 \%$ increase in the average size of individuals (reported as linear measurements, e.g. total length or carapace width) is equivalent to a much larger increase in individual biomass given the exponential relationship between length and weight. Furthermore, in addition to species richness having lower scope for change than density or biomass, reserve studies tend to quantify richness using species counts over a relatively small sample area (e.g. transect) and thus may often underestimate total species richness.

The global reserve effects presented here are consistent with previous analyses of fewer reserves (Halpern \& Warner 2002, Palumbi 2002, Gell \& Roberts 2003, Micheli et al. 2004). Our average reserve mean res-

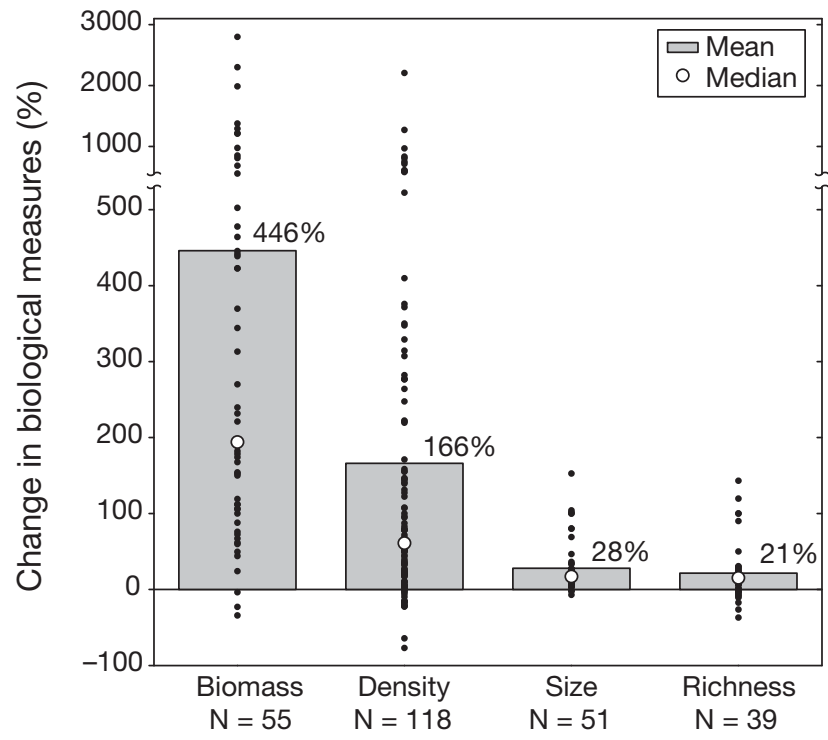

Fig. 2. Average (gray bars) and median ( $(\circ)$ percent change in biomass, density, organism size, and species richness calculated from reserve response ratios. All 4 biological variables show statistically significant increases (1-sample 2-tailed $t$-tests, $\mathrm{p}<0.0001$ for biomass, density, and organism size and $p=0.002$ for species richness). (•) Individual reserve responses. N: number of reserves for which each biological variable was measured

ponses are very similar to those of Halpern's (2003) smaller data set (present study vs. Halpern's [2003] biomass: 446 vs. $352 \%$; density: 166 vs. $151 \%$; organism size: 28 vs. $29 \%$; species richness: 21 vs. $25 \%$; Halpern 2003 percentages were calculated using mean reserve responses and excluding the few studies that did not meet the criteria used here, e.g. gray literature). Our substantially expanded data set illustrates that these biological impacts are robust. However, it is important to note the reserves in our data set may be better enforced than most. Many existing reserves have inadequate enforcement and high levels of poaching and as a result will show smaller or no responses to protection (e.g. Guidetti et al. 2008).

Although the vast majority of response ratios for all metrics indicated positive changes in reserves, the magnitude of the response varied enormously (Fig. 2). This variability is not surprising given that there are a host of factors that can affect both the magnitude and direction of an individual reserve response, including the species studied, characteristics of the reserve, and activities occurring outside the reserve or inside the reserve prior to protection. Furthermore, the distribution of responses had a pronounced skew for both biomass and density, with a few very large positive values. For these 2 metrics, the average response was substantially higher than the median response. Given the large variance in all metrics and the skew in some, the average response may be a poor predictor of the 
expected magnitude of response for any individual species, group of species, or an entire community within any particular reserve.

There was considerable variation in the number of species examined among the studies in our database, and studies examining more species might be expected to show lower responses because they average across species with positive and negative responses. However, there is no indication that our results are biased by the inclusion of studies investigating only a single or small number of species. We examined response ratios as a function of the number of species measured in each study; while there tends to be a wider range of responses (higher variance) for studies looking at a single or small number of species, the mean response ratio for each biological measure is relatively constant for studies looking at one or a few species compared to studies measuring an increasing number of species ( $p>0.1$ for all 4 biological variables)
(Fig. 3). Thus, given the consistency of positive response ratios in this broad synthesis and their large median and average values, there is strong evidence that marine reserves have important positive biological effects within their boundaries.

A more detailed examination of some of the higher values in our data set illustrates some of the factors that influence reserve responses, drawing particular attention to how intense fishing and subsequently extremely low levels of studied species outside the reserve can lead to exceptional positive responses. The highest density datum $(+2210 \%)$ is the Las Cruces Reserve in Chile, which represents the average of 5 studies measuring a variety of taxa including intertidal fishes, gastropods, and algae. Of these studies, the 2 with the highest values both quantified the density of an economically important gastropod species, Conchelepas conchelepas (loco), which was incredibly rare everywhere prior to reserve implementation and
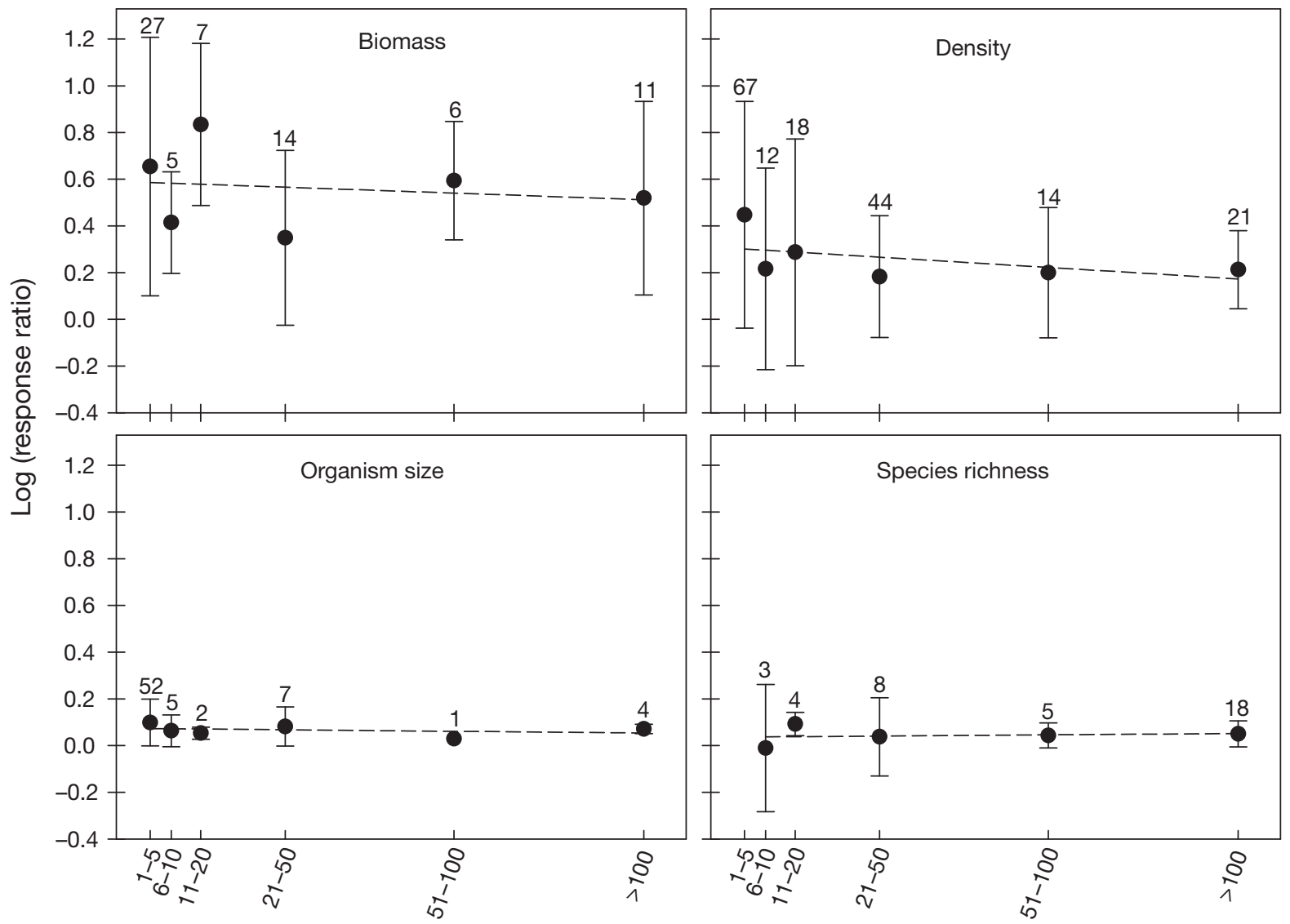

No. species studied

Fig. 3. Average study response ratios by number of species studied. Study response ratios were calculated using those studies for which we could determine the number of species measured within the following ranges: 1-5, 6-10, 11-20, 21-50, 51-100, and $>100$ species. Linear regression models were constructed for each biological variable using the mean study ratio in each bin ( $y$-variable) and the midpoint of each bin ( $x$-variable). Error bars: \pm SD. Numbers above error bars: number of studies included in each data point. All regressions are non-significant (biomass: $\mathrm{R}^{2}=0.028, \mathrm{p}=0.751$; density: $\mathrm{R}^{2}=0.259, \mathrm{p}=0.302$; organism size: $\mathrm{R}^{2}=0.105, \mathrm{p}=0.521$; richness: $\mathrm{R}^{2}=0.027, \mathrm{p}=0.790$ ) 
outside the reserve after protection (Castilla \& Duran 1985, Manriquez \& Castilla 2001). The highest biomass datum $(+2800 \%)$ is the Bongalonan Reserve in the Philippines, the subject of a single study measuring large predatory fishes in the families Serranidae, Lutjanidae, and Lethrinidae (Russ et al. 2005). As a third example, the second highest biomass datum is the subject of a study that examined a single economically important species; in the Governor Island reserve in Australia, rock lobster biomass was documented to be $2300 \%$ higher inside the reserve, due to very low biomass levels of lobster outside the reserve (Edgar \& Barrett 1999). While such extreme positive responses are rare, half of the reserve sites show biomass changes exceeding a $200 \%$ increase and density changes exceeding a $60 \%$ increase.

Some reserves show decreases in key biological variables. Several of the decreases in density are from a study in which percent cover of live hard coral was quantified for numerous reserves in the Philippines (Russ et al. 2005), with some reserves showing higher coral cover outside the reserve. For example, live coral cover was $64 \%$ lower inside the Canlucani Reserve after 2 yr of protection. Given the slow growth rates of hard corals, they may be slow to recover inside reserves. Although we did not examine the effect of duration of protection in the present study, it has been shown to be an important factor in explaining recovery of previously overfished ecosystems, particularly for slower growing species (e.g. Russ \& Alcala 2004).

Species richness decreased in a number of reserves, several of which are South African intertidal reserves in the Transkei region (Hockey \& Bosman 1986). Hockey \& Bosman (1986) found that intense human collecting acts as a source of disturbance, promoting coexistence among otherwise competing prey species, thereby increasing intertidal richness in unprotected areas. Whether we would predict an increase or decrease in species diversity in response to reserve protection likely depends on the level of human disturbance (i.e. fishing pressure) and predation in the system. As expected from the intermediate disturbance hypothesis and community succession theory (Connell 1978), diversity is likely to increase in reserves when fishing outside is more intense but may decrease in reserves when fishing is moderate to light outside the reserve. This is corroborated by studies examining reef fish biomass, density, and diversity over a gradient of human disturbance; with decreasing human disturbance, biomass increases consistently while density and diversity increase until top predators accumulate a threshold fraction of the total biomass in the system, leading to a decline in their prey (e.g. Sandin et al. 2008). This suggests that biomass may often be the best indicator of reserve performance.
Lastly, most of the data used in these analyses are from inside versus outside comparisons, as is true of other marine reserve meta-analyses. Thus, a general positive reserve effect may be an artifact of reserves being placed in better habitat or areas otherwise better able to support larger numbers and sizes of organisms. Alternatively, a positive reserve effect could be caused by the reserve displacing fishing effort to areas outside. In other words, if the outside 'control' area is faced with increasing fishing pressure due to reserve establishment, decreasing numbers or biomass of target species in these fished areas would lead to a positive response ratio even if there has been no change within the reserve.

Reserves do not appear to be placed in fundamentally better locations based on a comparison of biological measurements taken inside and outside of future

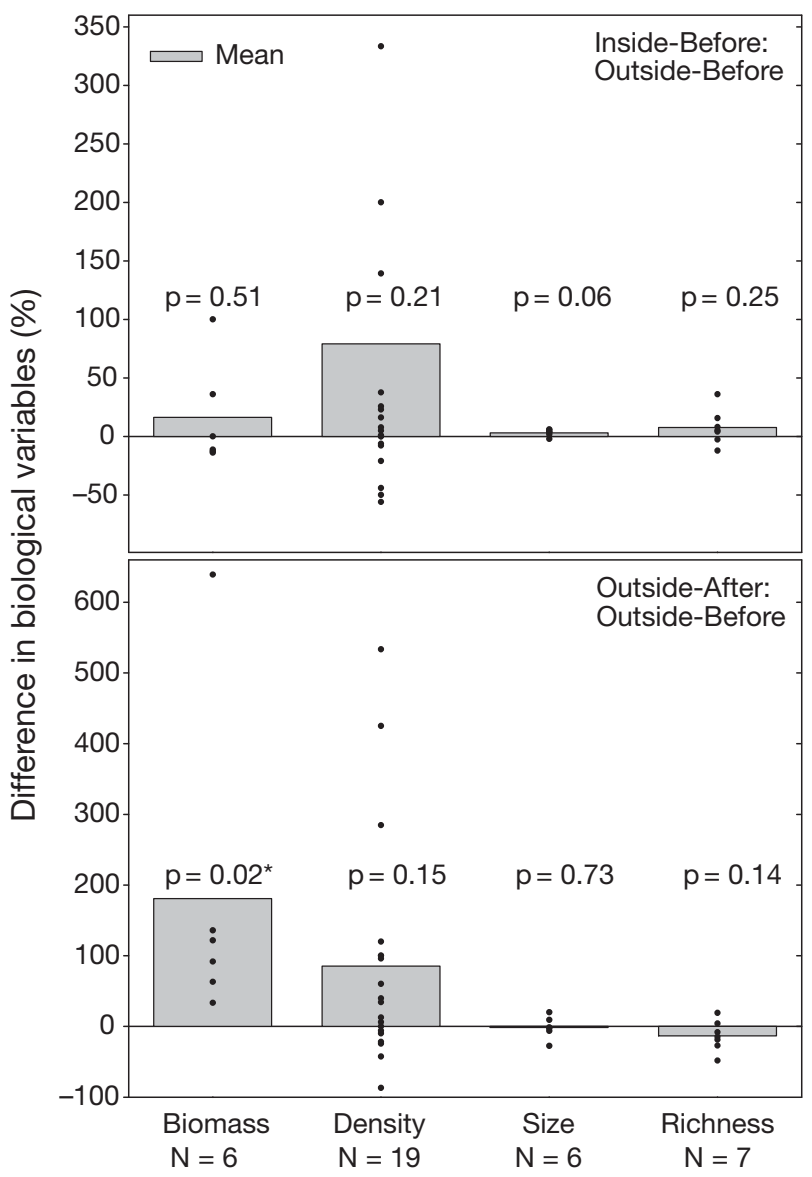

Fig. 4. Average (gray bars) percent difference in biomass, density, organism size, and species richness calculated from the ratios Inside-Before:Outside-Before (top panel) or Outside-After:Outside-Before (bottom panel). (•) Individual study responses. None of the biological variables show responses that are statistically different from zero, with the exception of biomass for the Outside-After:Outside-Before comparison (1-sample, 2-tailed $t$-tests). $\mathrm{N}$ : number of studies for which each biological variable was measured 
reserves before they are established (Fig. 4, top panel). While these response ratios are positive, they are not statistically significant (1-sample, 2-tailed $t$-tests, hypothesis mean log response ratios significantly different than zero, $\mathrm{p}>0.2$ for biomass, density, and organism size and $p=0.06$ for species richness). Furthermore, if the large increases in biological measures observed in the global data set (Fig. 2) were only a result of reserve placement, we would expect a significant effect in the Inside-Before:Outside-Before analyses at a power of 0.95 for density and 0.84 for biomass given their sample sizes (power analysis using error SD from the global analysis).

Areas outside reserves did not show declines in biological measures following reserve establishment. In fact, outside areas either exhibited no change or, in the case of biomass, a significant increase after the reserve was in place (Fig. 4, bottom panel; $p=0.02$ for biomass and $\mathrm{p}>0.1$ for density, organism size, and species richness). This increase suggests that reserves may benefit outside areas, possibly through the spillover of adults or the export of larvae over the long term. Thus, the global synthesis results may actually be underestimating the reserve effect given the large number of inside versus outside comparisons and their potential to show no change or slight increases outside reserves through adult spillover or larval export. Of course, these results must be interpreted with caution given that the sample sizes for these Before-After-Inside-Outside comparisons are much smaller than those for the global data set.

\section{Marine reserves in temperate versus tropical environments}

Despite the perception that many of the important fished species in temperate waters are too mobile or long-lived to be effectively protected by reserves (Shipp 2003, Blyth-Skyrme et al. 2006), we found that reserves in temperate environments tend to show effects that are as large, and in some cases larger, than those documented for reserves in the tropics (Fig. 5). The effects of marine reserve protection on individual size and species richness were similar across geographical regions (2-tailed $t$-tests, size: $\mathrm{p}=0.759$; richness: $p=0.133$ ). For biomass and density, there was a slight trend towards greater positive responses in temperate systems (biomass: $p=0.076$; density: $p=0.097$ ).

Given the tendency for temperate species to have higher adult mobility and longer larval dispersal relative to tropical species, it has been suggested that temperate reserves need to be far larger than is politically, socially, or economically feasible to meet stated management goals (Shipp 2003, Laurel \& Bradbury 2006).

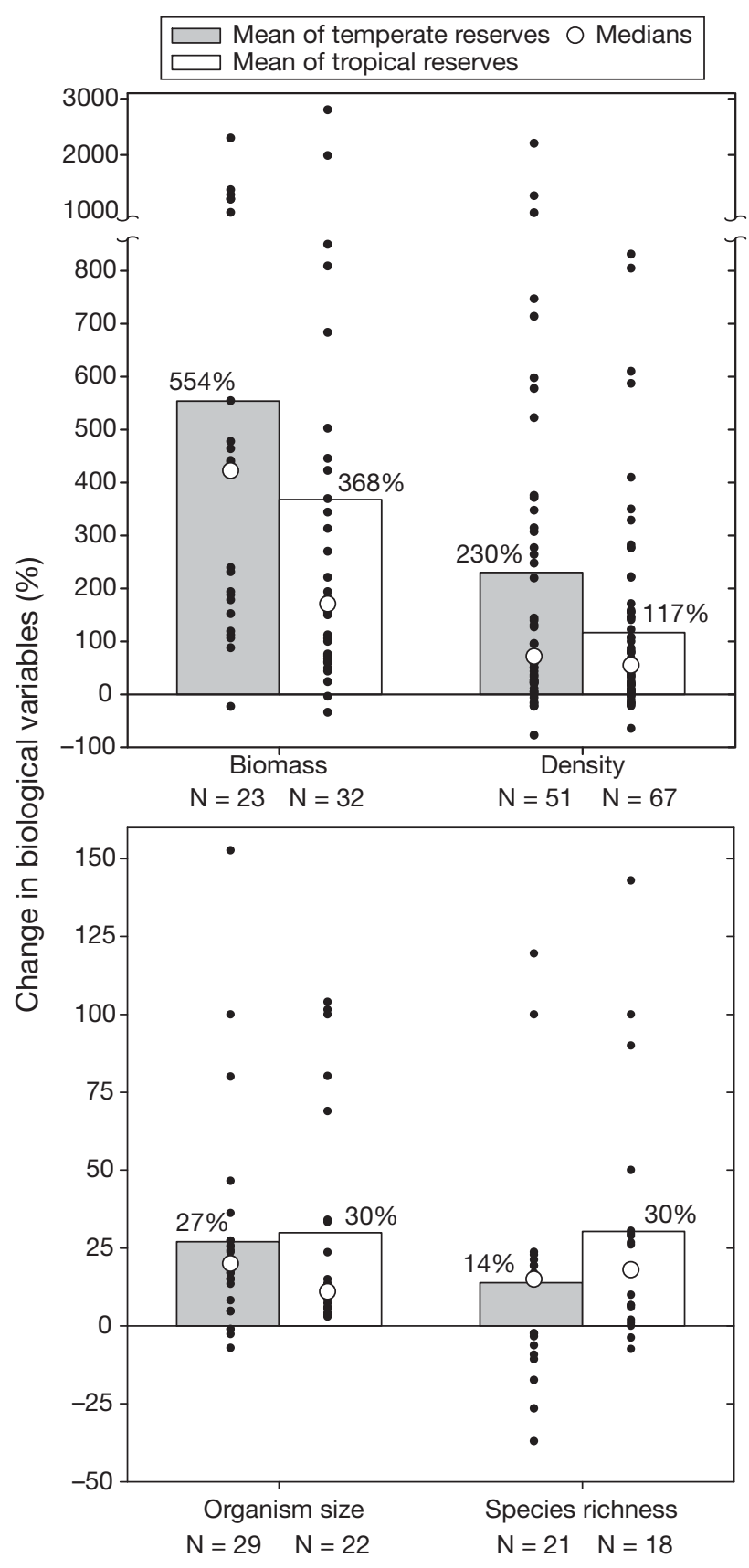

Fig. 5. Average (gray bars) and median $(\odot)$ percent change in biomass, density, organism size, and species richness, calculated from reserve response ratios, with data plotted separately for reserves in temperate versus tropical environments. (•) Individual reserve responses. Percent increases by environment are statistically significant in all cases except species richness in temperate reserves (1-sample, 2-tailed $t$-tests, temperate reserves: $\mathrm{p}<0.0001$ for biomass, density, and size and $p=0.166$ for richness; tropical reserves: $p<0.0001$ for biomass and density, $p=0.0002$ for size, and $p=0.003$ for richness)

In our database, however, temperate reserves did not differ from the tropical reserves in average area or in their distribution of areas ( $t$-test, $p=0.80$; Kolmogorov- 
Smirnov test, $\mathrm{p}=0.376 ; \mathrm{n}=108$ ). When we examined the studies for which a reliable estimate of reserve area was available, we found that reserve size does not appear to influence the relative magnitude of the reserve protection response for any of the 4 key biological variables, controlling for tropical versus temperate environment (Fig. 6). In fact, all relationships between reserve size and a response variable were nonsignificant with the exception of organism size $(\mathrm{p}=$ 0.034), and this relationship was negative in both temperate and tropical environments. Ecologically, a negative relationship between reserve size and biological variables is counterintuitive. However, these negative relationships are influenced by single outlier points (the smallest reserve in both analyses), which exert considerable leverage on the regressions (Cook's D = 0.34 and 0.57 ; all other points, Cook's D < 0.1). Both of these points are reserves represented by a single invertebrate species: a relatively fast-growing branch- ing coral in a tropical Israeli reserve (Coral Beach Reserve, 6 yr of protection at time of study) and an exploited gastropod species in a temperate Chilean reserve (Las Cruces Reserve, 11 yr). These data demonstrate that in some cases even small reserves can result in dramatic increases in average individual size, particularly when studies examine fast growing, largely immobile species that are heavily impacted outside the reserve. If these 2 points are removed, the relationship between reserve size and organism size response becomes non-significant $\left(R^{2}=0.032, \mathrm{p}=\right.$ $0.729, \mathrm{n}=43$; effect tests, reserve size: $\mathrm{p}=0.263$, ecosystem: $\mathrm{p}=0.702$, interaction term: $\mathrm{p}=0.722$ ).

The finding that reserve responses are not mediated by the size of the protected area is generally consistent with prior reviews (Gell \& Roberts 2003, Halpern 2003, Micheli et al. 2004). However, the marine reserves in our database (median size $=3.3 \mathrm{~km}^{2}$ ) and those of prior studies tend to be relatively small, potentially limiting

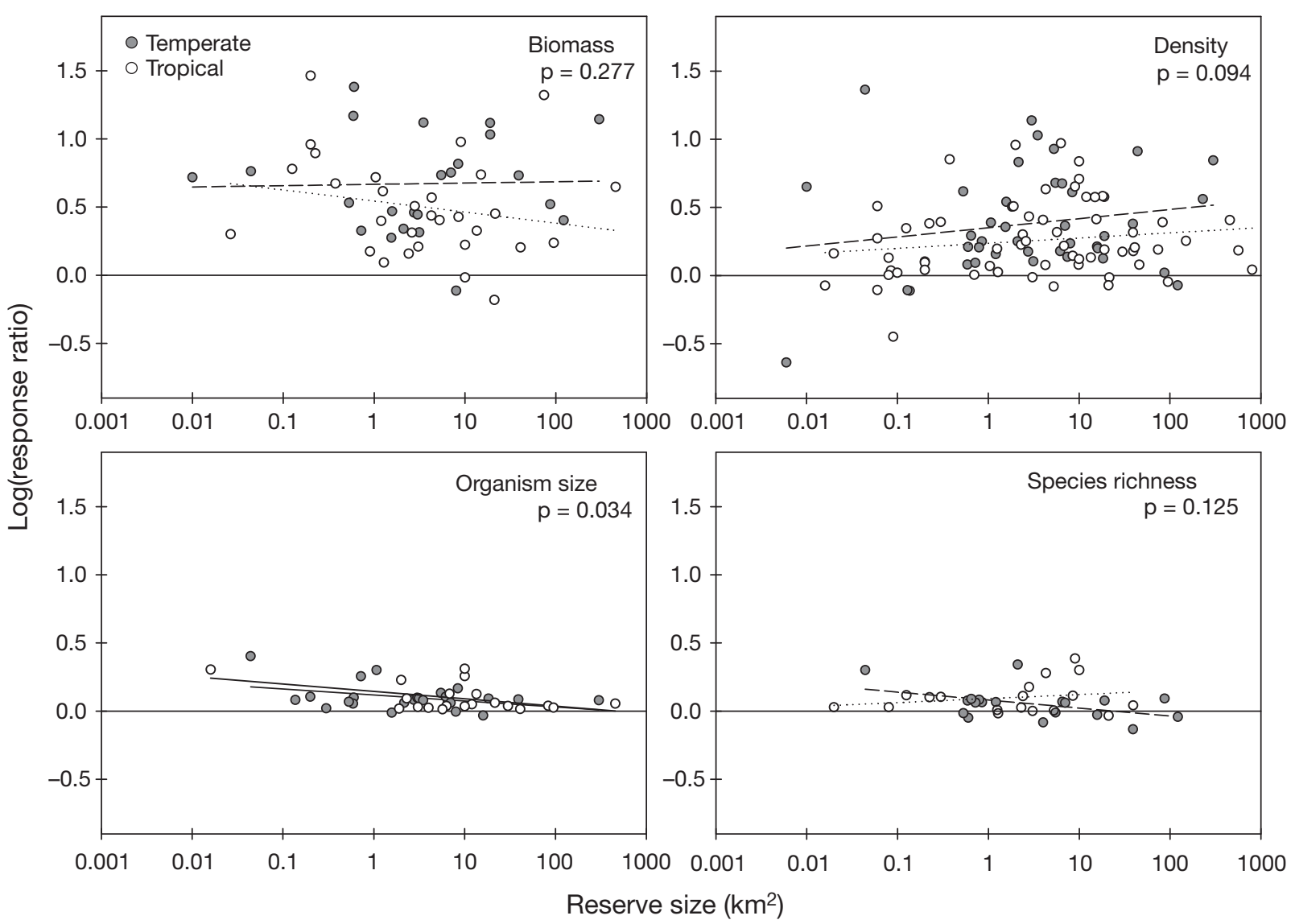

Fig. 6. Overall temperate and tropical marine reserve response ratios by reserve size and ecosystem. Linear regression models constructed with $\log ($ reserve size), ecosystem, and the reserve size $\times$ ecosystem interaction predicting log(response ratio) were fit separately for each metric. Non-significant regression lines $(p>0.05)$ are shown by dotted (tropical) or dashed (temperate) lines and significant regression lines $(\mathrm{p}<.05)$ are shown by solid lines (each line drawn along the $x$-axis over the range of the data). The significant relationships for organism size are both driven by single outlier points (see 'Results and discussion' for more details (biomass: $\mathrm{n}=53, \mathrm{R}^{2}=0.075, \mathrm{p}=0.277$; interaction term: $\mathrm{p}=0.399$; density: $\mathrm{n}=103, \mathrm{R}^{2}=0.062$, $\mathrm{p}=0.094$; interaction term: $p=0.638$; organism size: $\mathrm{n}=45, \mathrm{R}^{2}=0.189, \mathrm{p}=0.034$; effect tests, reserve size: $\mathrm{p}=0.004$, ecosystem: $\mathrm{p}=0.500$, interaction term: $\mathrm{p}=0.757$; species richness: $\mathrm{n}=37, \mathrm{R}^{2}=0.157, \mathrm{p}=0.125$; interaction term: $\mathrm{p}=0.05$ ) 
any meaningful tests of the effect of reserve size on biological responses. Our database also contains comparatively few studies examining highly mobile or migratory species for which reserve size may be a more critical factor. Lastly, given all the sources of variation influencing the reserve response (e.g. characteristics of the species studied, intensity of exploitation outside the reserve), it may also be difficult to detect an effect of reserve size across such a wide range of studies. Neither the present study nor most of the prior reviews were able to examine how the same suite of species responds to reserves of different sizes, an analysis that would provide a more definitive answer. Edgar \& Barrett (1997) studied 4 Tasmanian reserves and Claudet et al. (2008) studied 12 reserves in the Mediterranean and northeast Atlantic and both found evidence that biological responses may in fact scale with reserve size. Importantly, our results, for which the per unit area biological measures scale linearly with reserve size, do not suggest that reserve size is unimportant; for example, a doubling of per unit area biomass results in far more total biomass in a large versus small reserve.

\section{Differential effects of reserve protection among taxonomic groups}

Because reserve responses are likely to vary for different types of organisms, we examined reserve responses by broad taxonomic groupings (e.g. algae, invertebrates, and fishes) as well as different types of functional groups. Algal data did not have adequate sample sizes for any of the variables except density, for which there was no significant overall effect of reserves (Fig. 7). However, there was a tendency for temperate reserves to show higher density response ratios than tropical reserves ( $t$-test, $p=0.089$ ), with tropical reserves actually showing an average decrease in algal cover. This difference in the effect of reserve protection on algae in tropical versus temperate reserves matches typical expectations of reserve performance. Most tropical reserves include coral reefs, where a decline in algal abundance can lead to an increase in coral cover due to decreased spatial competition between algae and corals. In this situation,

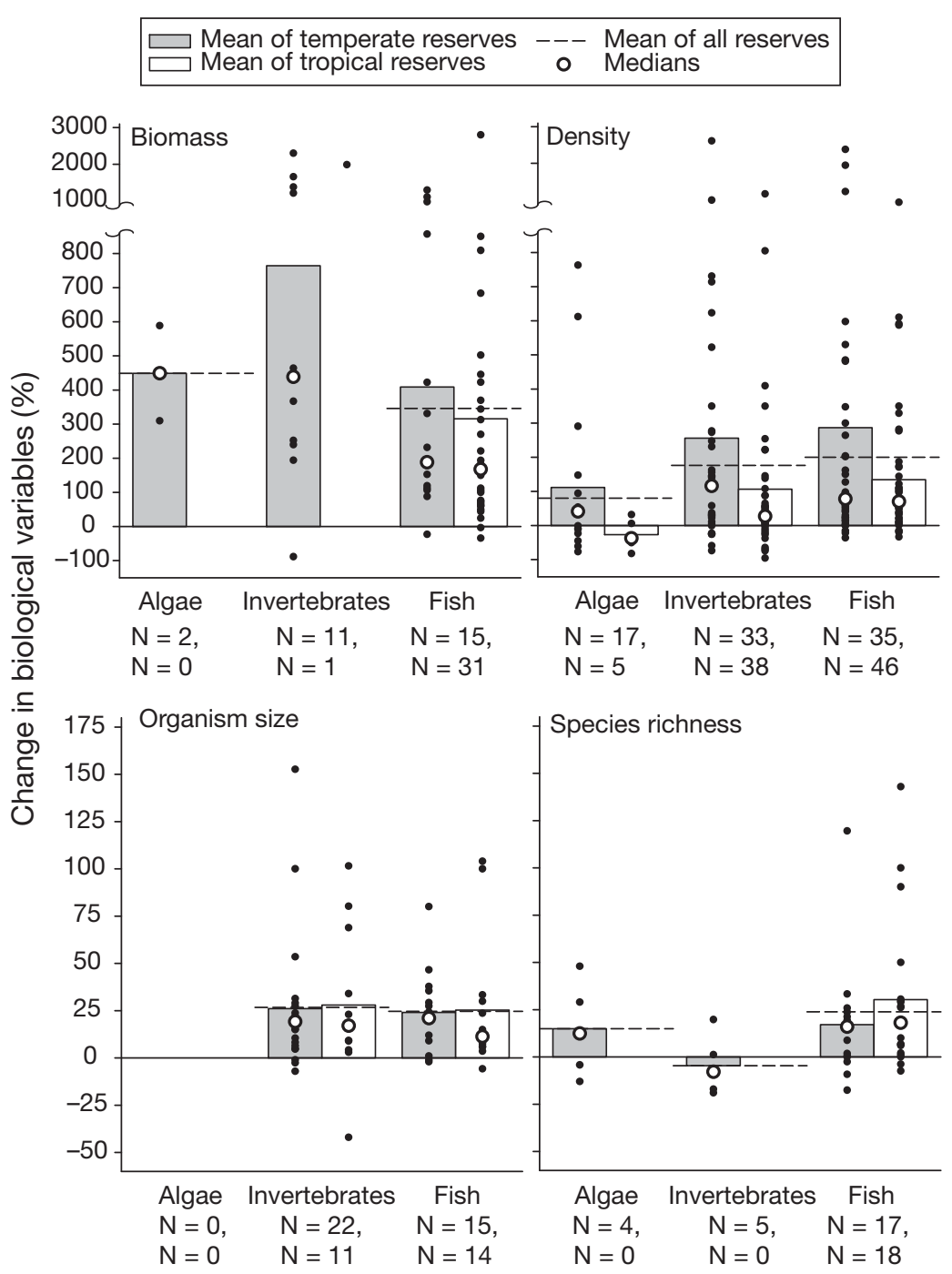

Fig. 7. Average (gray bars) and median (०) percent change in biomass, density, organism size, and species richness calculated from marine reserve response than no change (1-sample, 2-tailed $t$-tests, $\mathrm{p}<0.01)$ with the exception of algal responses (density: $\mathrm{p}=0.538$; biomass: $\mathrm{n}=2$; size: no data; richness: $\mathrm{p}=0.420$ ) and invertebrate richness $(p=0.469)$. Averages are plotted for all reserves and for temperate and tropical reserves separately. (0) Individual reserve responses by environment. N: number of reserves (temperate, tropical) for which each biological variable was measured

reserves can protect the herbivorous fishes that are frequently targeted by fishing, which reduce algal cover on the reef (Williams \& Polunin 2001, Mumby et al. 2006). In contrast, temperate reserves, particularly those in rocky reef habitats, often protect species that prey on urchins (the dominant herbivore in these systems), leading to an increase in algal cover.

Invertebrates and fishes showed significant positive average responses across all reserves for all 4 biological measures, with the exception of invertebrate species richness (Fig. 7). In comparison to fishes, inverte- 
brates tended to show higher but non-significant responses for organism biomass and density ( $t$-tests, density: $p=0.119$, biomass: $p=0.069$ ). Invertebrate densities showed negative responses in some reserves in addition to strong positive effects in many others, which may be the result of indirect effects and/or trophic dynamics (e.g. Shears \& Babcock 2003, Micheli et al. 2005).

To investigate the combined influence of environment and taxonomic group on the effects of reserve protection for density and organism size (biomass and richness lacked adequate sample sizes), we included environment (tropical versus temperate), taxonomic group (algae, invertebrates, and fishes for density; invertebrates and fishes for organism size), and the interaction term as predictor variables in a 2-way ANOVA. The overall model for density was significant $(\mathrm{p}=$ 0.004), as were the individual effects of environment and taxonomic group (effect tests; $\mathrm{p}=0.005$ and 0.003 , respectively). This result reflects 2 trends: (1) within each taxonomic group, there was a tendency for density responses to be higher in temperate versus tropical reserves ( $t$-tests, algae: $\mathrm{p}=0.089, \mathrm{n}=22$; fishes: $\mathrm{p}=$ $0.191, \mathrm{n}=81$; invertebrates: $\mathrm{p}=0.063, \mathrm{n}=71$ ); and (2) irrespective of latitude, the density response was significantly different across taxonomic groups (ANOVA, $\mathrm{p}=$ 0.017), with invertebrates and fishes showing higher positive mean responses than algae. In contrast, the environment-taxonomic group model was not significant for organism size ( $p=0.999)$, suggesting that increases in individual size are consistent for fishes and invertebrates across reserves in different geographic locations compared to the variation in responses that we documented for density. Lastly, there was no effect of latitude on biomass and richness of fish ( $t$-tests, biomass: $p=0.332$; richness: $p=0.272$ ), which parallels our results for overall reserve response ratios.
Beyond the differences we document for these broad taxonomic groups, individual species or groups of species are likely to respond differently to reserve protection based on a range of factors. For example, reserves are more likely to lead to large positive effects for species that are fished, intentionally or incidentally, or that are otherwise harmed by activities occurring in unprotected waters (Mosqueira et al. 2000, Cote et al. 2001, Micheli et al. 2004). Other characteristics that have been shown to mediate a reserve effect include trophic level (Micheli et al. 2004) and body size (Mosqueira et al. 2000). These more detailed analyses of species characteristics have only been conducted for fish, revealing a need for similar investigations for algae and invertebrates. However, it should be noted that species characteristics tend to explain a relatively low percentage of the variance in reserve responses (e.g. Micheli et al. 2004).

To assess the influence of algal and invertebrate characteristics, we conducted algae-only and invertebrate-only analyses using data extracted at the finest taxonomic resolution available. For algal functional groups, no group showed a statistically significant response to reserve protection (Table S3, available at www.int-res.com/articles/suppl/m384p033_app.pdf) and functional group was not a significant predictor of algal response (Table 2). The most dramatic response, albeit non-significant, was a $~ 500 \%$ average increase in leathery macrophytes (Table S3). The lack of significant responses is likely due in part to the relatively small sample sizes for algae, although it is also possible that algae respond idiosyncratically to reserve protection. Lastly, algae are more commonly measured in temperate reserves, particularly with adequate taxonomic resolution to allow for functional group classification. The only functional group for which there were data from both tropical and temperate reserves was corticated foliose algae, which increased in temperate

Table 2. ANOVA for algal functional groups and invertebrate characteristics predicting mean reserve response (using log response ratios). Pair-wise comparisons of target status categories for density indicated that 'high' and 'not targeted' are significantly different, but neither of those differ from 'low' (Tukey's HSD test). None of the trophic level categories for density are significantly different in pair-wise comparisons (Tukey's HSD test)

\begin{tabular}{|c|c|c|c|c|c|c|c|}
\hline \multirow[t]{2}{*}{ Characteristic } & \multirow[t]{2}{*}{ Categories } & \multicolumn{2}{|c|}{ Biomass } & \multicolumn{2}{|c|}{ Density } & \multicolumn{2}{|c|}{ Organism size } \\
\hline & & $\mathrm{p}$ & $\mathrm{N}$ & $\mathrm{p}$ & $\mathrm{N}$ & $\mathrm{p}$ & $\mathrm{N}$ \\
\hline Algal functional groups & $\begin{array}{l}\text { Crustose algae; filamentous algae; } \\
\text { articulated calcareous algae; corticated } \\
\text { foliose algae; corticated macrophytes; } \\
\text { leathery macrophytes }\end{array}$ & & & 0.763 & 41 & & \\
\hline \multicolumn{8}{|l|}{ Invertebrates } \\
\hline Adult mobility & Sessile; limited mobility; mobile & 0.663 & 16 & 0.578 & 96 & 0.372 & 39 \\
\hline Target status & High; low; not targeted & 0.190 & 17 & 0.008 & 86 & 0.495 & 36 \\
\hline Trophic level & $\begin{array}{l}\text { Herbivore; primary producer/filter } \\
\text { feeder; filter feeder; detritivore; omnivore; } \\
\text { invertivore }\end{array}$ & 0.066 & 23 & 0.022 & 107 & 0.414 & 42 \\
\hline Larval dispersal potential & Little/none; short distance; longer distance & & & 0.351 & 63 & 0.139 & 36 \\
\hline
\end{tabular}


reserves ( $49 \%$ increase, $\mathrm{n}=5$ reserves) and decreased in tropical reserves (15\% decrease, $\mathrm{n}=3$ reserves), although again these changes were not statistically significant.

In the invertebrate-only analyses, mollusks and arthropods showed significant increases as a result of reserve protection (Table S4, available at www.intres.com/articles/suppl/m384p033_app.pdf; for density and size for mollusks and for biomass, density, and size for arthropods). Examining finer taxonomic groupings, gastropods showed a significant increase in density and size, crabs showed an increase in density, and lobsters increased significantly in biomass, density, and size (Table S4). The dramatic increases documented for species like lobster are not surprising given that they are often heavily exploited and have relatively high population growth rates, allowing them to respond quickly to protection. In contrast, slow growing taxa such as hard corals did not show significant responses. Some taxonomic groupings, such as cephalopods and soft corals, had very small sample sizes and thus we could not adequately evaluate the effect of reserve protection for these groups.

When examining the effect of invertebrate characteristics on reserve response, we found that target sta-

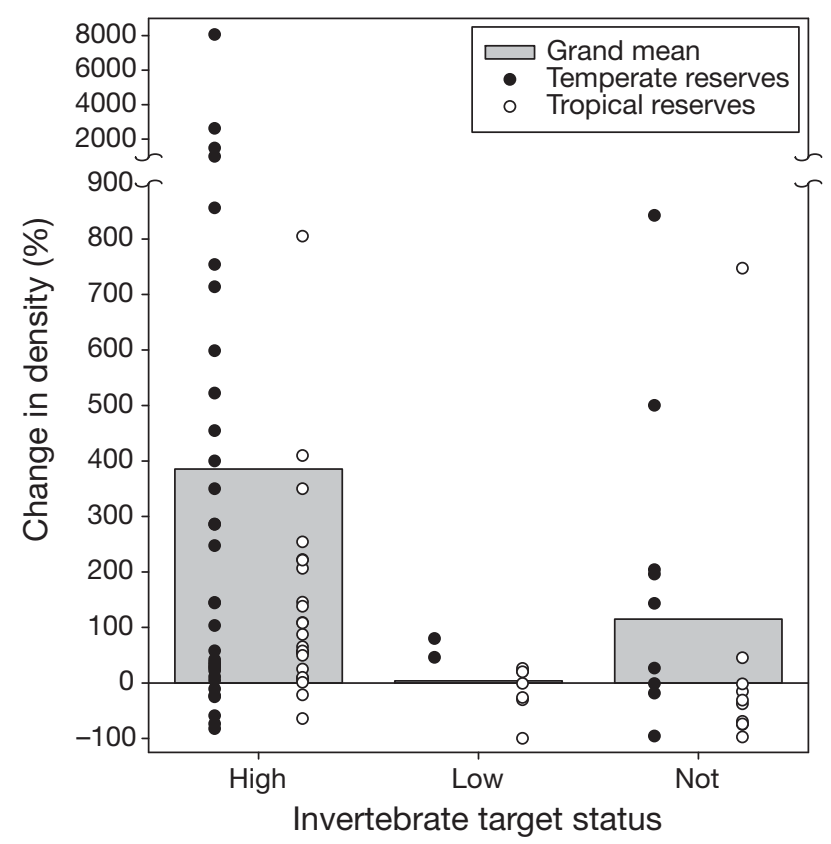

Fig. 8. Average (gray bars) percent change in density calculated from invertebrate-only mean reserve responses, by target status. $(\bullet, 0)$ Individual temperate and tropical reserve responses, respectively. There is a significant relationship for target status predicting reserve response (ANOVA, $p=0.008, n=86$ ). Pairwise comparisons of target status categories indicated that 'high' and 'not targeted' are significantly different, but neither of those differ from 'low' (Tukey's HSD test, $\mathrm{p} \geq 0.05$ ). See Table S4 (available at www.int-res.com/articles/suppl/ m384p033_app.pdf) for additional information tus and trophic level were both significant predictors of density responses (Table 2). As expected, highly targeted species showed the largest response, and these responses were relatively similar across tropical and temperate reserves (Fig. 8). For trophic level, predatory invertivores showed the largest increases (Table S2). These results are consistent with those for fish, where higher trophic levels tend to show greater responses to protection, likely because higher predators tend to be targeted by fisheries. Importantly, while these characteristics were significant predictors of density responses, they explain a relatively small percentage of the variance (ANOVA, $\mathrm{R}^{2}=0.111$ and 0.120 for target status and trophic level, respectively). Adult mobility and larval dispersal potential were not related to reserve responses for any of the biological measures (Table 2), although some of the movement and dispersal categories showed a significant effect of protection (Table S2). These significant responses are likely due to covarying characteristics that do influence a reserve response. For example, many of the species in the data set with longer distance dispersal are lobsters and crabs, which are heavily fished species with high population growth rates. This makes them ideal candidates for reserve protection irrespective of their dispersal characteristics.

The algal and invertebrate characteristics we investigated either were unrelated to a reserve response or explained only a relatively small portion of the variance in responses (Table 2), with similar results found previously for fishes (e.g. Micheli et al. 2004). Therefore, it is possible that variation in reserve responses for these species-level traits is driven by characteristics of the reserve (e.g. age, size) and the context of where the reserve is located, including intensity of fishing before reserve establishment and outside of the reserve, enforcement, and the management regime outside of the reserve. It is also possible that the specieslevel traits we were able to examine in this synthesis do not adequately capture the ecological or life-history traits that truly influence how these species respond to reserves. Both reserve characteristics and species traits are unfortunately difficult to assess but merit additional investigation.

\section{CONCLUSIONS}

Using a comprehensive global synthesis of ecological effects within no-take marine reserves, we demonstrate that reserve protection results in significant average increases in density, biomass, organism size, and species richness of the communities within reserve boundaries. However, it is important to note that 
reserves will not result in significant increases in all species, as demonstrated by the average decrease in algal density in tropical systems and the numerous negative invertebrate density data points. Additionally, our synthetic analysis demonstrates that these biological increases remain consistent as more scientific information about the impacts of marine reserves becomes available. Despite a perception that reserves are more likely to be effective in tropical regions, our results suggest that reserves result in positive effects at all latitudes and regions. Thus, reserves are likely to serve as globally important conservation and management tools when management goals include at least one of the biological responses reviewed in the present study.

Our analysis also revealed numerous critical information gaps. First, we note a general lack of peerreviewed reserve publications from certain regions of the world. Reserves exist in these locations, but it is difficult to assess whether implementation and enforcement are effective or whether these reserves can only be considered 'paper reserves.' Coordinated efforts to promote better dissemination of marine reserve science will greatly increase our understanding of the benefits and limitations of no-take marine reserves as an effective means of conservation and management. Similarly, the vast majority of reserves in our data set protect nearshore rocky or coral reef habitat, indicating a lack of marine reserve studies (and potentially marine reserves) in certain habitat types (e.g. soft sediment). This is particularly important for the interpretation of our comparison of tropical versus temperate reserve effects - while we have strong evidence that tropical and temperate reserves are similarly effective for reef ecosystems, we do not know whether this result holds for less structured habitat types.

For reserves that have been studied, there is a need for increasingly rigorous data collection. (1) Studies in which the reserve area is studied prior to and after implementation both outside and inside reserve boundaries are relatively rare. Such studies are critical because they effectively control for natural ecosystem dynamics and ecological variability on a regional scale and can help detect spurious reserve effects (Fig. 4). (2) Studies examining the same suite of species at reserves of different sizes within a region will be essential for better understanding how reserve effects scale with reserve size. Recent reviews have not compared data explicitly designed to investigate the effect of reserve area, and thus it is not surprising that they have found reserve effects to be constant across a range of reserve sizes (but see Claudet et al. 2008). (3) There is a need for accurate data and methods for quantifying the intensity of fishing and other exploitive activities outside of the reserve, management and reg- ulations outside of the reserve, and intensity of fishing inside the reserve prior to establishment, all of which may affect the response documented within a particular reserve, and which could thus help to explain the large amount of variation in reserve responses globally. The strong positive biological responses that we have documented around the world indicate that we can move past questions of reserve impacts across latitudes and taxonomic groups, and shift the focus to increasingly complex questions about the effects of marine reserves, both within and beyond their borders.

Acknowledgements. This work was supported by the Partnership for Interdisciplinary Studies of Coastal Oceans (PISCO), funded by the David and Lucile Packard Foundation and the Gordon and Betty Moore Foundation (contribution no. 335). This analysis contributed to The Science of Marine Reserves, an educational booklet funded by the David and Lucile Packard Foundation. S.E.L. was also supported by a NOAA Dr. Nancy Foster Scholarship. We thank S. Palumbi and P. Guarderas for discussions about the data set, W. McClintock for the global marine reserve map, A. Rassweiler for help with some analyses, and several anonymous reviewers for helpful comments on previous versions of the manuscript.

\section{LITERATURE CITED}

Blyth-Skyrme RE, Kaiser MJ, Hiddink JG, Edwards-Jones G, Hart PJB (2006) Conservation benefits of temperate marine protected areas: variation among fish species. Conserv Biol 20:811-820

Botsford L, Hastings A, Gaines S (2001) Dependence of sustainability on the configuration of marine reserves and larval dispersal distance. Ecol Lett 4:144-150

Browman HI, Stergiou KI (2004) Marine Protected Areas as a central element of ecosystem-based management: defining their location, size and number. Mar Ecol Prog Ser 274:271-272

Castilla JC, Duran LR (1985) Human exclusion from the rocky intertidal zone of central Chile: the effects on Concholepas concholepas (Gastropoda). Oikos 45:391-399

Claudet J, Osenberg CW, Benedetti-Cecchi L, Domenici P and others (2008) Marine reserves: size and age do matter. Ecol Lett 11:481-489

Connell JH (1978) Diversity in tropical rain forests and coral reefs. Science 199:1302-1310

Côté IM, Mosqueira I, Reynolds JD (2001) Effects of marine reserve characteristics on the protection of fish populations: a meta-analysis. J Fish Biol 59:178-189

> Edgar GJ, Barrett NS (1997) Short term monitoring of biotic change in Tasmanian marine reserves. J Exp Mar Biol Ecol 213:261-279

Edgar GJ, Barrett NS (1999) Effects of the declaration of marine reserves on Tasmanian reef fishes, invertebrates and plants. J Exp Mar Biol Ecol 242:107-144

> Fisher JAD, Frank KT (2002) Changes in finfish community structure associated with an offshore fishery closed area on the Scotian Shelf. Mar Ecol Prog Ser 240:249-265

> Gaines SD, Gaylord B, Largier JL (2003) Avoiding current oversights in marine reserve design. Ecol Appl 13(Suppl): $32-46$

Gaylord B, Gaines SD, Siegel DA, Carr MH (2005) Marine 
reserves exploit population structure and life history in potentially improving fisheries yields. Ecol Appl 15: 2180-2191

Gell FR, Roberts CM (2003) Benefits beyond boundaries: the fishery effects of marine reserves. Trends Ecol Evol 18: 448-455

> Gerber LR, Heppell SS, Ballantyne F, Sala E (2005) The role of dispersal and demography in determining the efficacy of marine reserves. Can J Fish Aquat Sci 62:863-871

Guidetti P, Sala E (2007) Community-wide effects of marine reserves in the Mediterranean Sea. Mar Ecol Prog Ser 335: 43-56

Guidetti P, Milazzo M, Bussotti S, Molinari A and others (2008) Italian marine reserve effectiveness: Does enforcement matter? Biol Conserv 141:699-709

$>$ Halpern BS (2003) The impact of marine reserves: Do reserves work and does reserve size matter? Ecol Appl 13(Suppl):117-137

Halpern BS, Warner RR (2002) Marine reserves have rapid and lasting effects. Ecol Lett 5:361-366

> Halpern BS, Warner RR (2003) Matching marine reserve design to reserve objectives. Proc R Soc Lond B Biol Sci 270:1871-1878

Halpern BS, Gaines SD, Warner RR (2004) Confounding effects of the export of production and the displacement of fishing effort from marine reserves. Ecol Appl 14: 1248-1256

> Halpern BS, Walbridge S, Selkoe KA, Kappel CV and others (2008) A global map of human impact on marine ecosystems. Science 319:948-952

Harley CDG, Randall Hughes A, Hultgren KM, Miner BG and others (2006) The impacts of climate change in coastal marine systems. Ecol Lett 9:228-241

Hedges LV, Gurevitch J, Curtis PS (1999) The meta-analysis of response ratios in experimental ecology. Ecology 80: 1150-1156

> Hockey PAR, Bosman AL (1986) Man as an intertidal predator in Transkei: disturbance, community convergence and management of a natural food resource. Oikos 46:3-14

> Jackson JBC (2008) Ecological extinction and evolution in the brave new ocean. Proc Natl Acad Sci USA 105: 11458-11465

Jennings S (2000) Patterns and prediction of population recovery in marine reserves. Rev Fish Biol Fish 10: 209-231

Kaiser MJ (2004) Marine protected areas: the importance of being earnest. Aquat Conserv 14:635-638

> Kaiser MJ (2005) Are marine protected areas a red herring or fisheries panacea? Can J Fish Aquat Sci 62:1194-1199

> Laurel BS, Bradbury IR (2006) 'Big' concerns with high latitude marine protected areas (MPAs): trends in connectivity and MPA size. Can J Fish Aquat Sci 63:2603-2607

Leslie HM (2005) A synthesis of marine conservation planning approaches. Conserv Biol 19:1701-1713

> Lester SE, Halpern BS (2008) Biological responses in marine no-take reserves versus partially protected areas. Mar Ecol Prog Ser 367:49-56

Lubchenco J, Palumbi SR, Gaines SD, Andelman S (2003) Plugging a hole in the ocean: the emerging science of marine reserves. Ecol Appl 13(Suppl):3-7

Manriquez PH, Castilla JC (2001) Significance of marine protected areas in central Chile as seeding grounds for the gastropod Concholepas concholepas. Mar Ecol Prog Ser 215:201-211

Mayfield S, Branch GM, Cockcroft AC (2005) Role and efficacy of marine protected areas for the South African rock lobster, Jasus lalandii. Mar Freshw Res 56:913-924
Micheli F, Halpern BS, Botsford LW, Warner RR (2004) Trajectories and correlates of community change in no-take marine reserves. Ecol Appl 14:1709-1723

Micheli F, Benedetti-Cecchi L, Gambaccini S, Bertocci I, Borsini C, Osio GC, Roman F (2005) Cascading human impacts, marine protected areas, and the structure of Mediterranean reef assemblages. Ecol Monogr 75:81-102

Mora C, Andréfouët S, Costello MJ, Kranenburg C and others (2006) Coral reefs and global network of marine protected areas. Science 312:1750-1751

> Mosquera I, Côté IM, Jennings S, Reynolds JD (2000) Conservation benefits of marine reserves for fish populations. Anim Conserv 3:321-332

> Mumby PJ, Dahlgren CP, Harborne AR, Kappel CV and others (2006) Fishing, trophic cascades, and the process of grazing on coral reefs. Science 311:98-101

O'Connor MI, Bruno JF, Gaines SD, Halpern BS, Lester SE, Kinlan BP, Weiss JM (2006) Temperature control of larval dispersal and the implications for marine ecology, evolution, and conservation. Proc Natl Acad Sci USA 104: 1266-1271

Paddack MJ, Estes JA (2000) Kelp forest fish populations in marine reserves and adjacent exploited areas of central California. Ecol Appl 10:855-870

Palumbi SR (2002) Marine reserves: a tool for ecosystem management and conservation. Pew Oceans Commission, Arlington, VA

Palumbi SR (2003) Population genetics, demographic connectivity and the design of marine reserves. Ecol Appl 13(Suppl):146-158

Palumbi SR, Gaines SD, Leslie H, Warner RR (2003) New wave: high-tech tools to help marine reserve research. Front Ecol Environ 1:73-79

Russ GR, Alcala AC (2004) Marine reserves: long-term protection is required for full recovery of predatory fish populations. Oecologia 138:622-627

Russ GR, Stockwell B, Alcala AC (2005) Inferring versus measuring rates of recovery in no-take marine reserves. Mar Ecol Prog Ser 292:1-12

Sale PF, Cowen RK, Danilowicz BS, Jones GP and others (2005) Critical science gaps impede use of no-take fishery reserves. Trends Ecol Evol 20:74-80

Sandin SA, Smith JE, DeMartini EE, Dinsdale EA and others (2008) Baselines and degradation of coral reefs in the Northern Line Islands. PLoS One 3:e1548

Shears NT, Babcock RC (2003) Continuing trophic cascade effects after 25 years of no-take marine reserve protection. Mar Ecol Prog Ser 246:1-16

Shipp RL (2003) A perspective on marine reserves as a fishery management tool. Fisheries 28:10-21

Steneck RS, Dethier MN (1994) A functional group approach to the structure of algal-dominated communities. Oikos 69:476-498

UNEP (United Nations Environment Programme) (2006) Marine and coastal ecosystems and human well-being: a synthesis report based on the findings of the Millennium Ecosystem Assessment. United Nations Environment Programme, Nairobi

White C, Kendall BE, Gaines S, Siegel DA, Costello C (2008) Marine reserve effects on fishery profit. Ecol Lett 11: 370-379

Williams I, Polunin N (2001) Large-scale associations between macroalgal cover and grazer biomass on mid-depth reefs in the Caribbean. Coral Reefs 19:358-366

Worm B, Barbier EB, Beaumont N, Duffy JE and others (2006) Impacts of biodiversity loss on ocean ecosystem services. Science 314:787-790 